\title{
Evaluating Tree Canopy Color Using Computerized Microdensitometry
}

\author{
David B. Headley and Robert G. Mower \\ Department of Floriculture and Ornamental Horticulture, Cornell University, Ithaca, NY 14853
}

\begin{abstract}
Additional index words. video imagery, qualitative color analysis, quantitative color analysis
Abstract. The color of a tree's canopy can provide much information about the tree's physiological status as well as its aesthetic function. We present a system for the qualitative and quantitative analysis of tree canopy color, based on a previously published algorithm. This algorithm determines (with a known accuracy) the Munsell hue, value, and chroma of a color using densitometric readings obtained through the use of color separation filters. This method was adapted for use with black-and-white video images. Combining the Rib algorithm with the techniques of photography, video imagery, scanning microdensitometry, and batch data computer processing, a semi-automated system was devised for the pixel-by-pixel color evaluation of a $512 \times 512$-pixel image. Based on a sample of 251 color chips, the following accuracies were obtained: Munsell hue - 86\%, Munsell value - 93\%, Munsell chroma -70\%, and Munsell color - $62 \%$. An example is provided that demonstrates how this system may be used to determine tree canopy color. By employing this technique, an estimation may be made of the colors and their relative quantities that are displayed by a tree's canopy.
\end{abstract}

The color of a tree's canopy (leaves, flowers, fruit, and branches) can provide useful information on its physiological and pathological condition as well as its aesthetic function. For example, the presence of yellowing leaves may indicate the extent of water stress of a drought-stressed red maple. The severity of leaf miner damage on a grey birch might be estimated by measuring the quantity of brown, damaged leaves in the tree's canopy. Similarly, the relative amount of red to green may be proportional to the amount of ripened fruit to leaves present on a cherry tree just before fruit harvest. Likewise, the abundance of white and pink flowers determines the visual effectiveness of a crabapple in bloom. Since canopy color is affected by many biological factors, it is not surprising that change in color often is used in scientific studies as an indicator of change in biological condition (Wright, 1969; Paclt, 1983).

For the sake of expediency in presenting a paper concerning the measurement of color, a few terms will be defined. Color may be considered as either a quality of light received from an object (the physical definition of color) or a visual experience (the psychological definition of color). Combining the physical and psychological aspects of color, the Munsell color system (Munsell, 1942) is a psychophysical system developed for color determination. A given color possesses the Munsell attributes of hue, value (brightness), and chroma (saturation). In this system, all colors are arranged according to their attributes into a three-dimensional "color space" known as the Munsell color solid. In an effort to simplify the classification of colors, the Inter-Society Color Council and the National Bureau of Standards (ISCC-NBS) has divided the Munsell color solid into 267 parts (Kelly and Judd, 1955). Each part or category is designated by a name that is descriptive of the colors in that category (examples: white, dark green, very light pink). A technique has been developed to determine the Munsell hue, value, and chroma of a color of a point on a photograph (Rib, 1966). This empirically derived method of color determination uses red, green, blue, and amber color separation filters, a densitometer, and a stepwise manual algorithm. We refer to this technique as the Rib algorithm.

Received for publication 18 Aug. 1988. The cost of publishing this paper was defrayed in part by the payment of page charges. Under postal regulations, this paper therefore must be hereby marked advertisement solely to indicate this fact.
Conventional color determination systems, such as color charts, may be used to determine canopy color. However, due to the often unwieldy nature of trees, the use of color charts to measure tree color can prove difficult and time-consuming. Moreover, not only a qualitative but also a quantitative measurement of the colors displayed by a tree would be exceedingly hard if done by hand, especially if the tree's canopy displays many colors. Possibly the most objective, accurate, and consistent way of evaluating tree canopy color would involve photography in conjunction with the video image processing technique of scanning microdensitometry. Scanning microdensitometry is the process by which a video image is broken down into its composing points or pixels and the optical density or brightness is determined for each one.

Scanning microdensitometry has been used in numerous investigations to study plant features. This technique has been used to estimate the area of an image covered by plant parts, such as for root length measurement (Voorhees et al., 1980; Upchurch and Ritchie, 1983; Barnett et al., 1987; Cuttingham et al., 1989) and for canopy coverage assessment (Everitt et al., 1984; Elliston and Miller, 1987; Gardner and Sydnor, 1987; Diebolt and Mudge, 1988; Thomas et al., 1988). Black-andwhite and color infrared photography in combination with image processing have been used to evaluate stress-induced canopy damage (Jackson and Wallen, 1975; Ladouceur et al., 1986). In the area of color analysis, spectral differences displayed by tree canopies were identified using color filtration and microdensitometry (Lillesand and Meisner, 1981; Kuhbauch, 1985). Here, the algebraic manipulation of red, green, and blue filter readings were performed to differentiate rudimentary color differences between all points composing an image. To date, no system has been developed for the automatic identification and quantification of real color of complexly colored biological identities.

In addressing the problem of evaluating tree canopy color, a technique is proposed. This method determines the colors and their relative quantities that are displayed by a tree. It employs the use of black-and-white photography, video imagery, scanning microdensitometry, and batch data processing. The objectives of this paper are to: 1) present a color evaluation method; 2) give an estimate of its accuracy; and 3) provide an example demonstrating how this method may be used to determine tree canopy color. 


\section{Materials and Methods}

The method for the evaluation of tree canopy color entails three major steps: 1) photographic; 2) video storage; and 3) image processing (Fig. 1). First, four black-and-white photographic prints are taken of the specimen tree, one photograph for each of four color separation filters. These four filtered photographs then are viewed individually by a television camera that feeds each image into an image processor. The image processor segments each image into an array of pixels and evaluates the optical density of each pixel. The optical density data then are computer-analyzed using the Rib algorithm. Each point making up the color image of the tree as seen from the camera's lens is evaluated for color, and points of like colors then are added together. This method combines the speed, objectivity, and accuracy of the Rib algorithm and the computer and applies them to the problem of tree canopy color analysis. Accuracy estimation has been made on a sample of color chips obtained from the Munsell color chart. Once it has been shown that a system can evaluate the color of a single point in a scene with a given accuracy, the system then can be automated to evaluate the color of all points composing a complete image.

To determine the accuracy of the color evaluation system, an 18-page abbreviated version of the Munsell Book of Color (1942) was used. This shortened version provides one color chip for each of the 267 ISCC-NBS color name categories, with the exception of 16 colors that are difficult to reproduce in paint pigments. For the exact Munsell hue, value, and chroma renovation for each color chip, refer to Headley (1985).

Each page of the color chart was photographed with a tripodmounted single-lens reflex Canon AE-1 programmable camera with a 50-mm f/1.8 Canon lens using Kodak Tri-X pan blackand-white print film. Each page was illuminated on either side by two tungsten-halogen lamps with a color temperature of 3400K (model Q255, 250-W, 120-V, Smith Victor, Griffith, Ind.). The lamps were aligned at a $45^{\circ}$ angle with the page to be photographed. The distance between the page and each lamp was $0.5 \mathrm{~m}$ and the distance between the page and the camera was also $0.5 \mathrm{~m}$. The illumination provided a constant f-stop in brightness across the page. A Kodak Wratten 80B color temperature conversion filter was placed over the camera lens to convert the light received from the lamp-illuminated page from $3400 \mathrm{~K}$ to $5500 \mathrm{~K}$. The filters used for color separation were Kodak Wratten 29 (red), 49 (blue), 61 (green), and 106 (visual).

Preliminary runs were conducted to determine the exposure that would yield the widest range in optical density between black and white for each filter (Table 1). Film density was checked with a Quanta Log transmittance densitometer (model FP1000, Macbeth Corporation, Newburgh, N.Y.).

Each page of the color chart was photographed once for each of the four color separation filters at the optimal exposure for a given filter. When photographed, a gray scale was placed next to each page as a standard reference. Each page was photographed with $1 / 8$ of the width and $1 / 6$ of the length of the

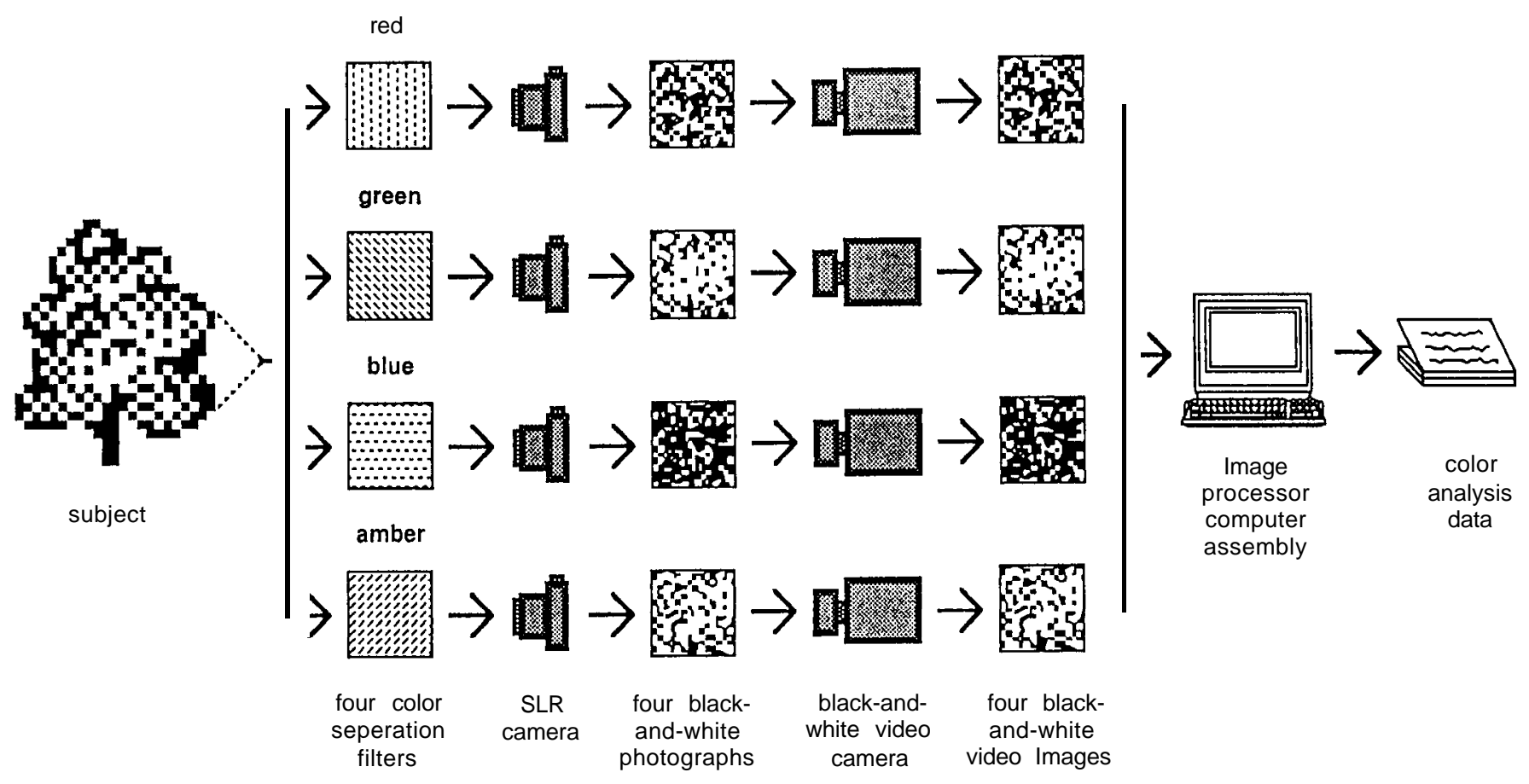

Fig. 1. Flow diagram describing the process of analyzing tree canopy color. Three major steps in this process are: step 1 -four black-andwhite photographs are taken of the specimen using four color separation filters; step 2-the four filtered photographs are viewed by a video camera to produce four black-and-white video images; and step 3-the four images are analyzed with an image processor/batch data processing assembly to produce color data of the specimen. 
Table 1. Camera settings for optimal film exposure for the four color separation filters.

\begin{tabular}{lccc}
\hline \hline Filter & $\begin{array}{c}\text { Shutter } \\
\text { speed }\end{array}$ & f-stop & $\begin{array}{c}\text { Adjusted } \\
\text { film speed }\end{array}$ \\
\hline Red & $1 / 8$ & 16 & 50 \\
Green & $1 / 8$ & 11 & 50 \\
Blue & $1 / 8$ & 11 & 25 \\
Amber & $1 / 30$ & 16 & 65 \\
\hline
\end{tabular}

viewfinder field bordering around it. This bordering of each frame was done to reduce the effects of lens fall-off on the image of the page. With each filtered set of color chart photographs, a calibrated 12-step reflectance density step tablet (gray scale) was photographed. The photographed tablet was later used at the image processor as an exposure calibration standard for each filter. In all, four sets of prints were made, each set containing one print of the step tablet and 18 prints of the 18 pages of the color chart.

The film was developed in Kodak D-76 developer for 8 min at $20 \mathrm{C}(68 \mathrm{~F})$ and then immersed in Kodak stopbath for $20 \mathrm{sec}$ and fixed in Kodak Rapid-Fix for $2 \mathrm{~min}$. The paper used for the prints was developed to normal contrast in 1 Kodak Dektol :2 water $(\mathrm{v} / \mathrm{v})$ solution for $2 \mathrm{~min}$.

Each of the prints of the color chart was illuminated by the same two tungsten-halogen lamps mentioned above, at a distance of $0.5 \mathrm{~m}$ and at an angle of $45^{\circ}$. Each print was then individually viewed by a black-and-white vidicon television camera (model 7120, Cohu Inc., San Diego, Calif.) at a distance of $0.5 \mathrm{~m}$. The camera lens aperature was set to an f-stop of 16 . The image of a given print as seen by the camera was then fed into an image processor (Image Processor/Software Package S570 version 3.0, International Image Systems, Milpitas, Calif.) and appeared on the processor's cathode ray tube (CRT). The image processor's software was run on a VAX 11/750 computer (VAX Computer Dealership, Ithaca, N.Y.).

In an effort to reduce noise in the image, three images of each print were averaged. To further reduce noise and to eliminate vignetting produced from the lens and lighting, three negative images of a blank white field also were taken. The six images were averaged by an algebraic operation employing the image processor's hard- and software. The resultant averaged image of the color chart then was registered on the processor's CRT. Samples of $\approx 10$ pixels were taken from each chip in the averaged image of the color chart page. The optical density for each chip was measured for each filter. Thus, for each chip in the abbreviated Munsell Color Chart, an averaged optical density (brightness) datum was recorded for each of the four filters. Using the four optical density data and the Rib algorithm, the Munsell hue, value, and chroma for each color chip in the abbreviated color chart was calculated.

This technique has been adapted to qualify and quantify tree canopy color (Headley, 1985). A plant of Parrotia persica C.A. Mey (Persian parrotia) photographed during its autumn foliar color change was used to demonstrate the use of this system of

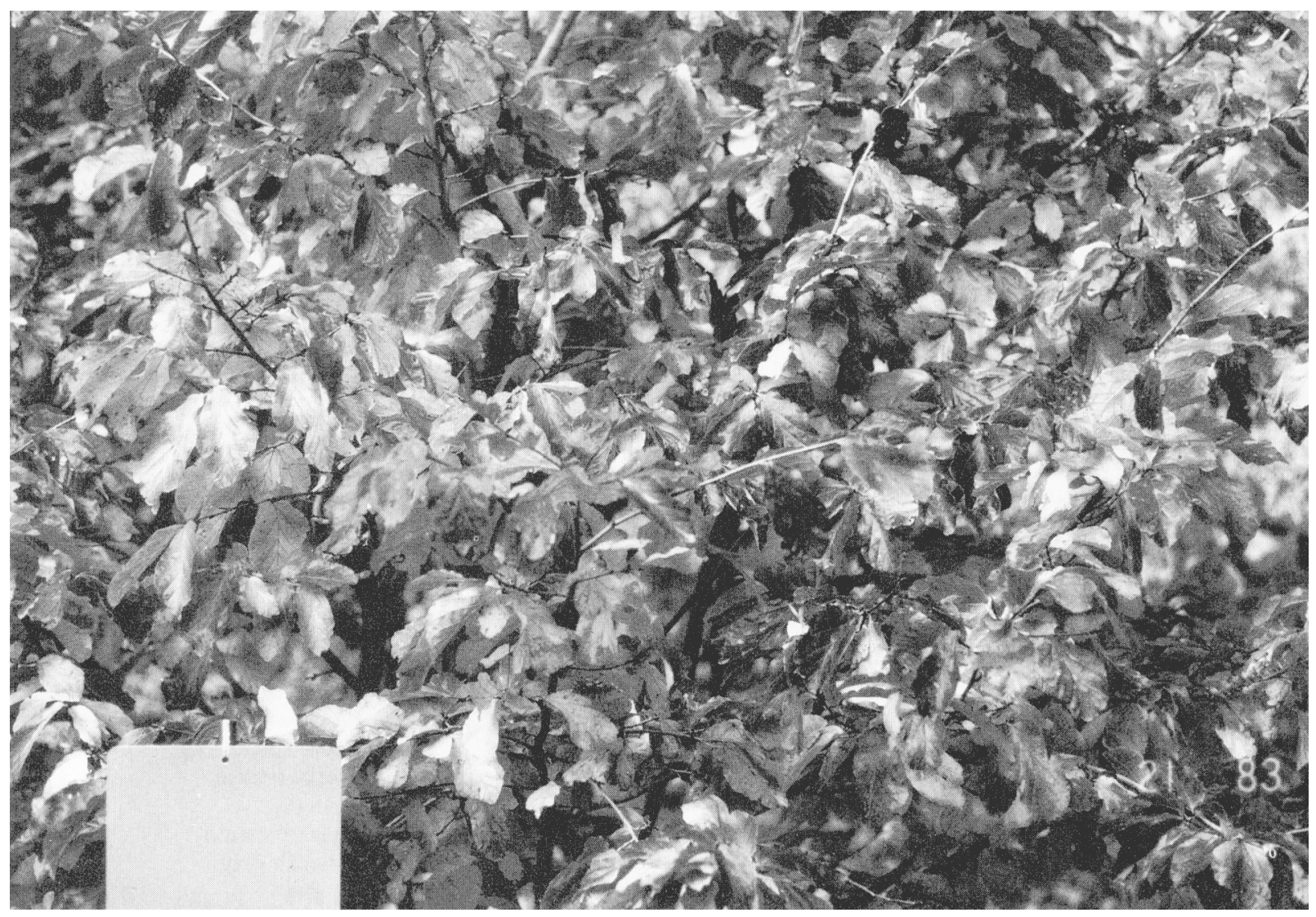

Fig. 2. Black-and-white photograph of the canopy of Parrotia persica used as a subject to demonstrate the color evaluation system. A fullcolor photograph of this image is in Headley (1985). 
color evaluation (Fig. 2). Parrotia was selected because it displayed many shades of green, red, orange, and yellow. A color photograph of the Parrotia is provided by Headley (1985). A gray card was included in the photograph of the canopy to aid in the correct exposure of the film. The tree canopy was photographed with a tripod-mounted camera using black-and-white print film and color separation filters in the manner described above. Prints $(12.7 \times 20.3 \mathrm{~cm})$ of the four filtered images then were viewed individually by the vidicon camera of the image processor assembly. Each one of the four filtered, black-andwhite video images was individually displayed on the image processor's CRT. Several shots of the same filtered image were averaged to reduce random noise. Each averaged filtered image was displayed on the CRT as a $512 \times 512$-pixel matrix. The image processor then measured the optical density of each pixel in the averaged, filtered image of the tree canopy. The optical density data of the four filtered images then were recorded onto magnetic computer tape at a density of 6425 bytes per inch $(25.4$ $\mathrm{mm})$. The tape containing the data for the four images then was accessed to an IBM 3081 computer (IBM Corp., Irving, Texas). The optical density data then were computer-analyzed using the PLI program CALCOLOR. CALCOLOR is a software package that uses the optical density data of four, $512 \times 512$-pixel matrices to determine the color of each point of the original color image of an object. This program employs the Rib algorithm, which sorts the resultant color data into the ISCC-NBS color categories. It then adds together all of the data within each category. The computer output is in the form of a table listing the 267 ISCC-NBS color categories and the number of pixels of the $262,144(512 \times 512)$ point matrix in each category. In other words, the computer output is the record of the colors in their respective quantities that were displayed by the Parrotia as seen through the camera's lens at the time the photographs were taken. The program CALCOLOR is very $\operatorname{long}(\approx 5000$ lines) and requires a considerable amount of computer work space. This program is available from us upon request.

\section{Results}

The calculated Munsell hue, value, and chroma of each chip in the abbreviated color chart were compared with the actual hue, value, and chroma of a given chip. If the calculated Munsell attribute was within \pm 1 Munsell step of the ISCC-NBS color name category, a tally was made for accuracy. If all three calculated Munsell attributes of a given color were accurate within the stated bounds, then the accurate identification of the color was obtained. Accuracy of the method in determining the color attributes and the color of chips in a representative sample of 251 chips from the Munsell Book of Color is as follows: hue $=86 \%$, value $=93 \%$, chroma $=70 \%$, and color $=62 \%$. Table 2 is a portion of the computer printout of the Parrotia color analysis. Recorded for each ISCC-NBS color category is the number of pixels (out of 262,144) that the image processing system determined were present in the original color image of the Parrotia. The complete printout of the Parrotia color analysis, as well as the calculated Munsell hue, value, chroma, and color ratings for each chip in the representative sample from the Munsell Book of Color, are provided by Headley (1985).

\section{Discussion}

When interpreting the accuracy of this method of color identification, the boundaries used to determine the accurate identification of a color should be considered. The accuracy of the
Table 2, Partial summary of the color analysis of the image of the Parrotia persica in Figure 2.

\begin{tabular}{|c|c|c|}
\hline 1 & Vivid pink & 487 \\
\hline 2 & Strong pink & 55 \\
\hline 3 & Deep pink & 55 \\
\hline 4 & Light pink & 0 \\
\hline 5 & Moderate pink & 211 \\
\hline 6 & Dark pink & 333 \\
\hline 7 & Pale pink & 0 \\
\hline 8 & Grayish pink & 0 \\
\hline 9 & Pinkish white & 0 \\
\hline 10 & Pinkish gray & 0 \\
\hline 11 & Vivid red & 8124 \\
\hline 12 & Strong red & 77 \\
\hline 13 & Deep red & 252 \\
\hline 14 & Very deep red & 2006 \\
\hline 15 & Moderate red & 1244 \\
\hline 16 & Dark red & 76 \\
\hline 17 & Very dark red & 1102 \\
\hline 18 & Light grayish red & 210 \\
\hline 19 & Grayish red & 2239 \\
\hline 20 & Dark grayish red & 0 \\
\hline 21 & Blackish red & 0 \\
\hline 22 & Reddish gray & 0 \\
\hline 23 & Dark reddish gray & 1 \\
\hline 24 & Reddish black & 0 \\
\hline 25 & Vivid yellowish pink & 485 \\
\hline 26 & Strong yellowish pink & 87 \\
\hline 27 & Deep yellowish pink & 400 \\
\hline 28 & Light yellowish pink & 4 \\
\hline 29 & Moderate yellowish pink & 156 \\
\hline 30 & Dark yellowish pink & 8 \\
\hline 31 & Pale yellowish pink & 32 \\
\hline 32 & Grayish yellowish pink & 0 \\
\hline 33 & Brownish pink & 0 \\
\hline 34 & Vivid reddish orange & 15 \\
\hline 35 & Strong reddish orange & 9 \\
\hline 36 & Deep reddish orange & 1 \\
\hline 37 & Moderate reddish orange & 83 \\
\hline 38 & Dark reddish orange & 68 \\
\hline 39 & Grayish reddish orange & 150 \\
\hline 40 & Strong reddish brown & 9 \\
\hline 41 & Deep reddish brown & 356 \\
\hline 42 & Light reddish brown & 102 \\
\hline 43 & Moderate reddish brown & 53 \\
\hline 44 & Dark reddish brown & 21 \\
\hline 45 & Light grayish reddish brown & 0 \\
\hline 46 & Grayish reddish brown & 0 \\
\hline 47 & Dark grayish reddish brown & 0 \\
\hline 48 & Vivid orange & 72 \\
\hline 49 & Brilliant orange & 1 \\
\hline 50 & Strong orange & 13 \\
\hline 51 & Deep orange & 18 \\
\hline 52 & Light orange & 0 \\
\hline 53 & Moderate orange & 40 \\
\hline 54 & Brownish orange & 911 \\
\hline 55 & Strong brown & 161 \\
\hline 56 & Deep brown & 604 \\
\hline 57 & Light brown & 122 \\
\hline 58 & Moderate brown & 13 \\
\hline 59 & Dark brown & 0 \\
\hline 60 & Light grayish brown & 0 \\
\hline 61 & Grayish brown & 0 \\
\hline 62 & Dark grayish brown & 0 \\
\hline 63 & Light brownish gray & 56 \\
\hline 64 & Brownish gray & 0 \\
\hline 65 & Brownish black & 0 \\
\hline 66 & Vivid orange yellow & 0 \\
\hline
\end{tabular}


Table 2. (Continued)

\begin{tabular}{llr}
\hline 67 & Brilliant orange yellow & 0 \\
68 & Strong orange yellow & 197 \\
69 & Deep orange yellow & 0 \\
70 & Light orange yellow & 0 \\
71 & Moderate orange yellow & 0 \\
72 & Dark orange yellow & 0 \\
73 & Pale orange yellow & 0 \\
74 & Strong yellowish brown & 0 \\
75 & Deep yellowish brown & 0 \\
76 & Light yellowish brown & 0 \\
77 & Moderate yellowish brown & 0 \\
78 & Dark yellowish brown & 0 \\
79 & Light grayish yellowish brown & 0 \\
80 & Grayish yellowish brown & 0 \\
\hline
\end{tabular}

Rib algorithm in identifying a given color's hue is $93 \%$, its value $100 \%$, and its chroma $98 \%$, within \pm 1 Munsell step of its true Munsell notation (Rib, 1966). Compare this accuracy with that arrived at using the Rib algorithm in conjunction with the densitometric abilities of the image processor assembly. The accuracy for the adapted method is $86 \%$ for hue, $93 \%$ for value, and $70 \%$ for chroma, all within \pm 1 Munsell step of the correct ISCC-NBS color name category. This broader "confidence interval" was used, not because it masks some of the error of the system, but because it is used by the computer program developed by us for the automated color evaluation of an image (Headley, 1985). Since the ISCC-NBS categories are not of equal size, these accuracies may be deceiving. Only more extensive sampling would provide more reliable assessment of accuracy. This image processing method theoretically should have the same accuracy as stated above in identifying colors of pixels in a 262,144-pixel matrix as it has in identifying the color of a single pixel.

The printout from the Parrotia color analysis gives the number of pixels in each Munsell color category present in the original color image of the Parrotia (Table 2). From this number, the percent of the total number of pixels in the pixel matrix may be calculated, where: (number of pixels in a color category) $\div$ 262,144 pixels $\times 100 \%=$ percent of total number of pixels that are in the color category. This number then maybe related directly back to the percentage of the canopy that displayed that color.

Limits in this method's accuracy allow for the incorrect identification of such colors as brilliant purple as being present on a canopy of the Parrotia as well as the identification of many pixels in the gray and black categories (Headley, 1985). The system is often unable to distinguish similar colors that are in adjacent Munsell color categories (Headley, 1985). Also, the system has difficulty discriminating colors of low saturation (low chroma) from the neutral colors of white, gray, and black. If lower color resolution is acceptable, the working accuracy of this system could be improved by clustering similar color categories into larger groups. For example, by grouping the categories of vivid green, brilliant green, and strong green into one large category, it maybe possible to improve the system's ability to correctly identify bright green color. Compensation for some of the error in the color data may occur with an examination of a color photograph of the subject while studying the color data output. If, for example, there is a large portion of the subject canopy that exhibits colors that are very dark and that the computer color data output shows a large amount of black on the canopy, then one may assume with some confidence that the analysis had classified most of those colors as black. The amount of black, as determined by the analysis, could then be assumed to be roughly equivalent to the proportion of the canopy exhibiting dark colors.

When using this method for analyzing tree canopy color, there are many factors that may affect the resultant color data. These factors may be categorized according to the step they come into play in the color analysis process. A list of these factors is provided (Table 3). A discussion of these factors that affect accuracy of color determination maybe found in Headley (1985).

In improving the accuracy of any technique, the accuracy of the individual components must be considered. The three major components of this system are: 1) the photographic color separation equipment; 2) the image processing assembly that takes the analog reading received from the vidicon television camera and digitizes it into optical density data; and 3) the computer software that converts the optical density data into color data using the Rib algorithm. Photographic color separation is made

Table 3. Factors affecting recorded color data of a tree canopy, grouped according to what step they come into play in the color analysis process.

I) Step 1-Photography

Factors involved at the point of color data origination Illumination

Intensity

Color temperature

Direction of illumination (i.e., solar zenith angle)

Evenness of illumination of the subject

Glare

Shadows

Characteristics of subject

Pigmentation

Epidermal characteristics

Pubescence

Glaucousness

Leaf overlap

Leaf tilt

Canopy geometry

Canopy coverage

Movement of subject

Inclusion of background scenery in image

Ambient weather conditions

Effect of distance between subject and camera on resolution

Factors involved at point of color data acquisition and storage

Lens fall-off

Lens vignetting

Camera shake

Film

Spectral sensitivity

Exposure

Pre- and post-exposure storage time

Development process

II) Steps 2 and 3-Video imagery and image processing

Factors involved at the point of color data analysis

Precise registration (overlap) of the four black-and-white color separation images

Video camera/image processor assembly

Resolution

Accuracy of gray level discrimination

Electronic noise

Accuracy of color determination by program equipped with $\mathrm{Rib}$ algorithm 
reliable and consistent by calibration and through the use of standardized film exposure and developing technique. Also, the method developed by Rib (1966) is fairly accurate in analyzing color from photographs. Therefore, the loss of system accuracy must occur in the part that produces the optical density data. Possibly, the vidicon camera is the weak link in the system and improvement in its ability to discriminate gray levels may yield better results.

Within the limits of its accuracy, the technique maybe used to determine the colors and their relative quantities that are displayed by a tree's canopy. There are numerous applications of the method for the qualitative and quantitative analysis of tree canopy color. For example, the amount of flowers or fruits in a tree's canopy may be estimated by measuring the relative amounts of specific colors displayed by its canopy. This information can be related back to the tree's visual effectiveness or to fruit yield. Similarly, the amount of discolored foliage due to some pathological, entomological, or physiological stress may be estimated. The amount of foliar autumn coloration or variegation may be determined. Trees in different locations or of different genotypes may be compared with respect to colorindicated traits. A time course study monitoring change in tree canopy color may be performed employing the technique. This method may be applied not only to trees but to other plants or plant parts or even to entire scenes for the fairly rapid and objective analysis of color.

\section{Literature Cited}

Barnett, C.E., R.A. White, A.H. Petrovic, and G.L. Good. 1987. An automated apparatus for measuring root length. HortScience 22:140144.

Cuttingham, M., M.B. Adams, R.J. Luxmore, W.H. Post, and D.L. DeAngelis. 1989. Quick estimate of root length using a video image analyzer. Can. J. For. Res. 19:335-340.

Diebolt, K.S. and K.W. Mudge. 1988. Use of a video-imaging system for estimating leaf surface area of Pinus sylvestris seedlings. Can. J. For. Res. 18:377-380.

Elliston, R. and L.D. Miller. 1987. Mapping leafy spurge with color video and micro-computer image processing. Proc. West. Soc. Weed Sci. 40:61-63.

Everitt, J.H., H.W. Gausman, and S.J. Ingle. 1984. Pubescence of
Texas lantana affects leaf spectra and imagery. Color aerial photography in the plant sciences and related fields: Proc. of the 9th biennial wkshp. on color aerial photography in the plant sciences. Amer. Soc. Photogram. 9:89-97.

Gardner, T.J. and T.D. Sydnor. 1987. Preliminary studies in photographic determination of tree shade capacities. HortScience 22(1): 145148.

Headley, D.B. 1985. A system for the descriptive, qualitative, and quantitative evaluation of tree canopy color employing the technique of computerized scanning microdensitometry. MS Thesis, Cornell Univ., Ithaca, N.Y.

Jackson, H.R. and V.R. Wallen. 1975. Microdensitometer measurements of sequential aerial photographs of Phaseolus vulgaris infected with Xanthomonas phaseoli. Phytopathology 65:961-968.

Kelly, K.L. and D.B. Judd. 1955. The ISCC-NBS method of designating colors and dictionary of color names. Natl. Bur. of Stand. Cir. 553.

Kuhbauch, W. 1985. Anwendungsmöglichkeiten der quantitativen Bildanalyse mit Echtfarbenerkennung in der pflanzen baulich-botanischen Forschung. Angew. Bot. 59:209-218.

Ladouceur, G., R. Allard, and S. Ghosh. 1986. Semi-automatic survey of crop damage using color infrared photography. Photogram. Eng. Remote Sensing 52(1):111-115.

Lillesand, T.M. and D.E. Meisner. 1981. Applications of scanning microdensitometry in selected plant science case studies. Color aerial photography in the plant sciences and related fields: Proc. of the 8th biennial wkshp. on color aerial photography in the plant sciences. Amer. Soc. Photogram. 8:127-136.

Munsell, A.H. 1942. Munsell book of color vol. 2. Munsell Color Co., Balitmore, Md.

Paclt, J. 1983. A chronology of color charts and color terminology for naturalists. Taxon 32(3):393-405.

Rib, H.T. 1966. An optimum multisensory approach for detailed engineering soil mapping. vol. 2. Purdue Univ., W. Lafayette, Ind. Joint Highway Res. Proj. 22.

Thomas, D.L., F.J.K. daSilva, and W.A. Cromer. 1988. Image processing technique for plant canopy cover evaluation. Amer. Soc. Agr. Eng. 31(2):428-434.

Upchurch, D.R. and J.T. Ritchie. 1983. Root observations using a video recording system in mini-rhizotrons. Agron. J. 75:1009-1015.

Voorhees, W.B., V.A. Carlson, and E.A. Hallover. 1980. Root length measurement with a computer controlled digital scanning microdensitometer. Agron. J. 72:847-851.

Wright, W.D. 1969. The measurement of color. Hilger \& Wath, London. 